OPEN ACCESS

Edited by:

Vida Abedi,

Geisinger Health System,

United States

Reviewed by:

Yanfei Zhang,

Geisinger Health System,

United States

Agnieszka Waśkiewicz,

Poznan University of

Life Sciences, Poland

Aurelio Cafaro,

Istituto Superiore di Sanità, Italy

${ }^{*}$ Correspondence:

Donald L. Sodora

don.sodora@cidresearch.org

Specialty section:

This article was submitted to

Nutritional Immunology,

a section of the journal

Frontiers in Immunology

Received: 08 September 2017 Accepted: 07 December 2017

Published: 22 December 2017

Citation:

Wood LF, Wood MP, Fisher BS, Jaspan HB and Sodora DL (2017)

$T$ Cell Activation in South African

HIV-Exposed Infants Correlates

with Ochratoxin A Exposure.

Front. Immunol. 8:1857.

doi: 10.3389/fimmu.2017.01857

\section{T Cell Activation in South African HIV-Exposed Infants Correlates with Ochratoxin A Exposure}

\author{
Lianna Frances Wood', Matthew P. Wood'2, Bridget S. Fisher', Heather B. Jaspan ${ }^{3,4}$ and \\ Donald L. Sodora ${ }^{2 *}$ \\ ${ }^{1}$ Department of Microbiology and Immunology, Albert Einstein College of Medicine, New York, United States, ${ }^{2}$ Center for \\ Infectious Disease Research, Seattle, WA, United States, ${ }^{3}$ Divisions of Paediatrics, Institute of Infectious Disease and \\ Molecular Medicine, University of Cape Town, Cape Town, South Africa, ${ }^{4}$ Department of Infectious Disease, Seattle \\ Children's Research Institute, Seattle, WA, United States
}

The introduction of non-breastmilk foods to HIV-infected infants is associated with increased levels of immune activation, which can impact the rate of HIV disease progression. This is particularly relevant in countries where mother-to-child transmission of HIV still occurs at unacceptable levels. The goal of this study was to evaluate the levels of the toxic food contaminant ochratoxin A (OTA) in HIV-exposed South African infants that are either breastfed or consuming non-breast milk foods. OTA is a common mycotoxin, found in grains and soil, which is toxic at high doses but has immunomodulatory properties at lower doses. Samples from HIV-exposed and HIV-unexposed infants enrolled in prospective observational cohort studies were collected and analyzed at birth through 14 weeks of age. We observed that infants consuming non-breast milk foods had significantly higher plasma levels of OTA at 6 weeks of age compared to breastfed infants, increasing until 8 weeks of age. The blood levels of OTA detected were comparable to levels observed in OTA-endemic communities. OTA plasma levels correlated with HIV target cell activation (CCR5 and HLADR expression on CD4+ T cells) and plasma levels of the inflammatory cytokine CXCL10. These findings provide evidence that elevated OTA levels in South African infants are associated with the consumption of non-breastmilk foods and activation of the immune system. Reducing infant OTA exposure has the potential to reduce immune activation and provide health benefits, particularly in those infants who are HIV-exposed or HIV-infected.

Keywords: infant, feeding, breastfeeding, contamination, HIV

\section{INTRODUCTION}

Exclusive breastfeeding is strongly recommended by the World Health Organization for all infants, irrespective of HIV status. Exclusive breastfeeding has been associated with reductions in rates of gastrointestinal infections, childhood asthma, obesity, and childhood leukemia (1). Furthermore, exclusively breastfed infants have been shown to have lower levels of pro-inflammatory bacterial taxa in their stool and reduced gut permeability when compared to formula-fed infants (2-4). In addition to providing unique nutritional and immunological benefits, exclusive breastfeeding is especially beneficial in areas where access to safe, clean food, and water is compromised (5). Nevertheless, many infants in low-income settings are introduced to non-breast milk foods early in life (6). 
Breastfeeding is particularly important for HIV-infected infants, whose disease progresses more rapidly with replacement foods (6-10). One factor contributing to increased HIV disease progression in infants that are not exclusively breastfed may be exposure to foodborne, immunomodulatory toxins that could accelerate immune activation, a key predictor of HIV disease progression $(11,12)$. Ochratoxin A (OTA) is one of the most common small molecule mycotoxins worldwide, including in South Africa (13-15), and has been implicated in renal disease, immune modulation, and cancer (16). OTA is produced by a number of species of both Aspergillus and Penicillium fungi, which are found in soil (17-20) and water (21), but can also grow on food products $(22,23)$. Indeed, OTA contamination has been detected in a vast range of agricultural products, including cereals, grapes, spices, medicinal herbs, chocolate, and meat from animals raised on OTA-contaminated feed (24).

At high doses, OTA is cytotoxic, resulting in tumorigenesis, nephrotoxicity, and immunosuppression $(25,26)$. However, with lower levels of exposure, OTA induces excessive inflammation, including induction of TNF- $\alpha$, IL-6, and IL- 1 production by multiple cell types, both in vitro and in animal models (27-29). OTA's immunomodulatory activity is believed to be mediated by its robust induction of reactive oxygen species, paired with suppression of oxidative stress response pathways, which in turn stimulate pro-inflammatory pathways $(30,31)$. This is particularly important in the context of HIV, since oxidative stress increases HIV replication, which may increase disease progression (32). Here, we provide evidence that OTA levels are elevated in non-breastfed South African infants and that this elevation is associated with T cell activation in HIV-exposed South African infants.

\section{MATERIALS AND METHODS}

\section{Study Participants}

Infants evaluated in this study were enrolled at birth from the maternity ward at the Site B Clinic in Khayelitsha, Western Cape, South Africa, between 2010 and 2012. This study cohort has been previously described in Ref. (33). Inclusion criteria were term pregnancy (36 weeks gestational age or greater at birth), birth weight $>2.4 \mathrm{~kg}$, maternal age 18 years or older, known maternal HIV status, HIV DNA PCR negative at birth or at 6 weeks of age (where applicable), and no potential household tuberculosis contact. All mothers of eligible infants were verbally informed of potential risks and benefits of the study, and signed an IRB-approved consent form in their preferred language, either English or isiXhosa. At birth, 2, 6, 8, and 14 weeks of age, mothers completed an interviewer-assisted survey that included detailed information about the foods consumed by the infant, their health status since the last study visit, including receipt of vaccinations, and maternal health status, including the mother's most recent CD4 count, if $\mathrm{HIV}$-infected. In addition, infants received a full physical exam, including anthropometrics and evaluation for any oral or skin conditions. Finally, blood (EDTA by venipuncture; $\mathrm{BD}, \mathrm{CA}$, USA) was collected at each study visit. Two cohorts of infants were included, one cohort included infants born to HIV-infected mothers and were, therefore, HIV-exposed infants, and a second cohort of HIV-unexposed infants was also included where indicated. All HIV-infected mothers received antiretroviral treatment per South African national guidelines. Demographic data of these two cohorts are presented in Table 1. The low-income setting of this study resulted in difficulties with infant retention, and blood samples at some of the desired time points were not available. There were no demographic differences between infants that were retained in the study and those that were lost to follow-up (33). We acquired the largest number of samples at week 6 , and a decreased number of samples at weeks 2 (28 infants), 8 (15 infants), and 14 (11 infants). The majority ( $>60 \%$ ) of the infants at weeks 2,8 , and 14 were also evaluated at the week 6 time point.

Infants were defined as breastfed if they had consumed only breastmilk up to the time of sample collection, per maternal report. Non-breastfed infants were infants whose mother's no longer fed them breast milk (i.e., replacement fed). Infants who consumed both breast milk and non-breast milk foods at the time of sample collection were considered mixed fed.

\section{Blood Processing}

Blood samples were stored at room temperature in an air conditioned room (temperature no greater than $30^{\circ} \mathrm{C}$ ) for no more than $6 \mathrm{~h}$ before transport. Blood was centrifuged, and plasma was aliquoted and frozen at $-80^{\circ} \mathrm{C}$. Peripheral blood mononuclear cells (PBMCs) were isolated from the remaining cells, using Ficoll (Sigma, MO, USA) density gradient separation. PBMCs were slowly cooled to $-80^{\circ} \mathrm{C}$ in fetal bovine serum (FBS) (Biochrom, $\mathrm{UK})+10 \%$ DMSO (Sigma, MO, USA), and transferred to liquid nitrogen for storage.

\section{Assessment of T Cell Activation by Flow Cytometry}

Frozen PBMCs were thawed at $37^{\circ} \mathrm{C}$, washed, and resuspended in PBS (Sigma, MO, USA) + 1\% FBS (Biochrom, UK), and cell counts were quantified with a Guava automated cell counter (EMD Millipore, Darmstadt, Germany).

Only infants who had not received BCG vaccination were included in these analyses, the influence of BCG vaccination on immune activation was assessed in a previous study (33). The focus on only non-BCG vaccinated infants enabled us to remove this potential immune stimulation as a confounder from the analysis, as BCG vaccination independently increases T cell activation $(33,34)$. Each sample was stained with optimized volumes

TABLE 1 | Demographics of study participants in each cohort.

\begin{tabular}{lcc}
\hline & HIV-exposed $(\boldsymbol{n}=\mathbf{5 8})$ & HIV-unexposed $(\boldsymbol{n}=\mathbf{2 6})$ \\
\hline Gender male, $n(\%)$ & $20(38.5)$ & $\mathrm{N} / \mathrm{A}$ \\
Gestational age, weeks & $40(38-40)$ & $40(38-40)$ \\
Maternal CD4, cells/mm $\mathrm{mm}^{3}$ & $332(238-477)$ & $\mathrm{N} / \mathrm{A}$ \\
Birth weight, $\mathrm{g}$ & $3,140(2,820-3,300)$ & $3,100(2,940-3,240)$ \\
Breastfed, $n(\%)$ & $15(26 \%)$ & $8(31 \%)$ \\
\hline
\end{tabular}

Values are reported as median vales and interquartile ranges or $n$ and \%, as indicated. N/A, not available. 
of antibodies to evaluate $\mathrm{T}$ cell activation as previously published in Ref. (33). One million cells were stained in a 96-well plate with Live/Dead-Violet (Invitrogen, CA, USA) for $20 \mathrm{~min}$ at room temperature, then with anti-CCR5-APC (BD, CA, USA) at $37^{\circ} \mathrm{C}$ for $15 \mathrm{~min}$, and then stained with anti-CD4-PerCP-Cy5.5 (BD, CA, USA), anti-CD38-PE-Cy7 (eBioscience, CA, USA), anti-HLADR-PE (BD, CA, USA), and anti-CD8-QDot605 (Invitrogen, CA, USA) for $20 \mathrm{~min}$ at room temperature. Samples were then washed with PBS, permeabilized with CytoFix/CytoPerm (BD, CA, USA), washed twice with Permawash (BD, CA, USA), and then stained intracellularly with anti-Ki-67-FITC and anti-CD3AlexaFlour700 (BD, CA, USA) for $20 \mathrm{~min}$ at room temperature. A final wash was performed and then cells were resuspended in Cell Fix (BD, CA, USA), transferred to a polysterene FACS tube and collected on a Becton Dickinson LSR II flow cytometer within $24 \mathrm{~h}$ of staining. All flow cytometry data were compensated and analyzed, using Flow Jo v10 (Treestar, OR, USA). Samples with less than $80 \%$ lymphocyte viability were not included in the analysis (Live/Dead negative).

\section{Ochratoxin Quantification}

Ochratoxin A was quantified in infant plasma by competitive ELISA in accordance with the manufacturer's instructions (Helica, CA, USA). Each sample and control was processed in duplicate. Absorbance was measured on a SpectraMax plate reader (Molecular Devices, CA, USA) at $450 \mathrm{~nm}$. OTA levels in each sample were calculated based on a 5-parameter regression of known standards. Values calculated below the lowest standard were assigned the value of the lowest standard. Interassay variability of the assay was minimal (CV 11.2\%), based on repeat testing of 10 samples. Lower limit of detection was $80 \mathrm{pg} / \mathrm{mL}$ for HIV-exposed infants and $100 \mathrm{pg} / \mathrm{mL}$ for HIV-unexposed infants.

Formula and infant food samples were collected from the three non-breastmilk foods most commonly reported by mothers of infants in our study. All samples were advertised as "Baby Cereal," procured from grocery stores in Cape Town and were manufactured in 2014. Sample 1 was Nestle's Nestum Baby Cereal Regular and was composed of: wheat flour, brown sugar, flavoring, calcium carbonate, sodium phosphate, vitamins (A, B1, B2, B6, B12, C, D3, E, biotin, niacin, folic acid, pantothenic acid), maltodextrin, sodium chloride, ferrous fumarate, zinc sulfate, Bifidobacterium lactis, and potassium iodide. Sample 2 was Purity's Baby's First Cereal Rice and was composed of: rice flour, maltodextrin, non-hydrogenated vegetable fat, tricalcium phosphate, dicalcium phosphate, vitamins (A, C, D, pantothenic acid, thiamine, riboflavin, pyridoxine, biotin, folic acid, cyanocobalamin), and minerals (magnesium, iodine, iron zinc). Sample 3 was Nestle's Cerelac Baby Cereal with Milk Regular and was composed of: wheat flour, skimmed milk powder, brown sugar, vegetable oil, flavoring, sodium chloride, calcium carbonate, sodium phosphate, maltodextrin, vitamins (A, B1, B2, B6, B12, C, D3, E, biotin, niacin, folic acid, pantothenic acid), ferrous fumarate, B. lactis, zinc sulfate, and potassium iodide. These samples were removed directly from their packaging and tested for OTA by LC-MS/MS, performed by Silliker Inc. Samples were suspended in acetonitrile, ascorbic acid, and water solution and extracted in a stomacher for $2 \mathrm{~min}$. Samples were then cooled for $1 \mathrm{~h}$ at $2-8^{\circ} \mathrm{C}$ and an aliquot was diluted in water, and then vortexed and spun down. The diluted sample was then injected into LC-MS/MS [parent ion $(\mathrm{M}+\mathrm{H})$ 404, daughter ions 239 (quantitation trace) and 221 (confirmation trace)]. Lower limit of detection for this assay was $0.8 \mu \mathrm{g}$ OTA per kilogram of food (LOD $0.8 \mathrm{ppb}$ and LOQ $5 \mathrm{ppb}$ ).

\section{Measurement of Plasma Cytokines/ Chemokines}

Plasma samples from 0-, 2-, and 6-week time points from the infants who were not administered the BCG vaccine were thawed on ice. Prior to cytokine measurements, plasma was centrifuged at $10,000 \mathrm{~g}$ for $10 \mathrm{~min}$ to remove debris and supernatants were used to determine GM-CSF, IFN- $\alpha$, IFN- $\gamma$, IL- $1 \beta$, IL- 8 , CXCL-10 (IP-10), MCP-1, MIP-1 $\beta$, TNF- $\alpha$, IL-12p70, and IL-10 concentrations in plasma samples using Milliplex ${ }^{\mathrm{TM}}$ Human Cytokine kits (Millipore, MA, USA). The lower limit of detection of these assays range between 3.2 and $7.2 \mathrm{pg} / \mathrm{mL}$ for the cytokines measured. Data were collected using a Bio-Plex $200^{\mathrm{TM}}$ Suspension Array Reader (Bio-Rad Laboratories, CA, USA) and analyzed using Bio-Plex manager software (version 4) (Bio-Rad Laboratories, CA, USA). Cytokine levels that were below the lower limit of detection of the assay were reported as the mid-point between the lowest concentrations measured for each cytokine and 0.

\section{Statistical Analysis}

Statistics were performed in Prism 5 (Graphpad, CA, USA) and $\mathrm{R}$ (35). Unpaired $t$-tests were used after testing for normality with D'Agostino and Pearson omnibus normality test ( $p$-value for all populations $>0.05$ ). Where appropriate, multiple comparison correction was performed using the Holme stepdown approach (36). Spearman correlations were used for evaluating correlations. Multivariate analysis was performed in $\mathrm{R}$, using the $\mathrm{lm}$ function and the following equation:

$$
\begin{aligned}
y= & \text { OTA }+1.5^{\text {(gestational age })}+\text { male }+\log _{10}(\text { maternal cd } 4 \text { count }) \\
& +\log _{2}(\text { visit age })
\end{aligned}
$$

where $y=$ immune activation marker of interest. If the parameter gained normal distribution with transformation, exponential or $\log$ transformation was applied to the parameter before further analysis.

\section{RESULTS}

\section{Cohort Demographics}

To assess plasma levels of the mycotoxin OTA in HIV-exposed, uninfected infants, we evaluated samples from infants enrolled in two studies in Khayelitsha, South Africa (37), an informal settlement just outside of Cape Town, South Africa, which followed infants until 14 weeks of age. A subset analysis, based on availability of samples for these studies, was performed on 2-, 6-, 8 -, and 14-week-old infants. There was a slight overrepresentation of female infants in the HIV-exposed infants (Table 1). In the HIV-exposed infants, maternal CD4 count ranged from 71 to over 1,000 cells $/ \mathrm{mm}^{3}$, although the median CD4 count was above 
200 cells $/ \mathrm{mm}^{3}$. Consistent with the eligibility criteria, median gestational age was $>38$ weeks and birth weights ranged from 2,500 to $4,100 \mathrm{~g}$.

\section{OTA Plasma Levels in South African Infants}

Ochratoxin A plasma levels at 2 weeks of age were relatively low for both breastfed and non-breastfed infants $(131$ and $151 \mathrm{pg} / \mathrm{mL}$, respectively; Figure 1). However, at 6 weeks of age, OTA plasma levels increased in non-breastfed infants (151 to $250.5 \mathrm{pg} / \mathrm{mL}$ ), while no increase was observed between 2 and 6 weeks in the exclusively breastfed infants (Figure 1). Longitudinal analysis of non-breast fed infants determined that OTA levels continued to increase in a linear fashion until 8 weeks of age, followed by a slight, but significant, decline at 14 weeks of age, the last time point available for analysis (Figure 2). The OTA levels detected in the plasma of South African infants are within the range of plasma levels observed in adults from OTA-endemic communities (16).

In addition, OTA analysis was also performed on plasma from HIV-unexposed infants at 14 weeks of age. Since many HIV-negative mothers feed their infants both breastmilk and non-breastmilk foods (mixed feeding), we also included these infants in the comparison (Figure 3). Non-breastfed infant plasma contained elevated levels of plasma OTA when compared to both the exclusively breastfed and mixed fed infants (294 and $100 \mathrm{pg} / \mathrm{mL}$, respectively). These levels were comparable to week 14 samples from the HIV-exposed infants (Figure 3, open red squares). Interestingly, mixed fed infants had low to intermediate levels of plasma OTA, suggesting that variable degrees of nonbreastmilk food intake results in a broader range of plasma OTA. This finding provides evidence that elevated plasma OTA levels can be observed in both the HIV-exposed and HIV-unexposed infant groups.

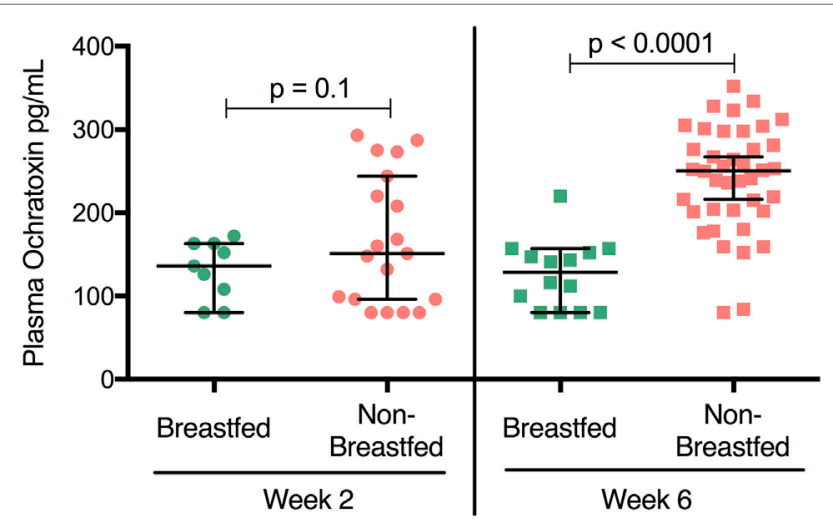

FIGURE 1 | Plasma ochratoxin A (OTA) levels are elevated in non-breastfed, South African infants. 2-week-old breastfed $(n=9)$ and non-breastfed $(n=19)$ infants were comparable in their levels of plasma OTA $(p=0.1$, Student's $t$-test). In contrast, at 6 weeks of age non-breastfed $(n=42)$ infants showed higher levels of OTA (increased nearly two fold) compared to their breastfed counterparts $(n=14 ; p<0.0001)$. Bars reflect the median OTA plasma level for each population. The lower limit of detection for the OTA ELISA assay was $80 \mathrm{pg} / \mathrm{mL}$. All infants were HIV-exposed.

\section{OTA Exposure and Immune Activation}

To evaluate the immunological effects associated with OTA exposure, the activation status of CD4 T cells was measured in infant PBMCs. Two T cell populations that were of particular interest were HIV target cells (those that co-express the HIV-receptor and co-receptor, CD4 and CCR5) (38) and the activated CD4 T cells (identified by MHC class II molecule HLA-DRexpression) $(39,40)$. CCR5 and HLA-DR expression on CD4 T cells were evaluated at 2,6 , and 8 weeks of age in HIV-exposed, non-breastfed infants. In these infants, OTA plasma levels positively correlated with frequencies of CCR5 ( $r=0.44 ; p=0.008$; Figure 4A) and HLADR-expressing CD4 T cells ( $r=0.36 ; p=0.02$; Figure 4B). These findings indicate that increased levels of HIV target cells and CD4+ T cell activation, which promotes HIV replication, is associated with elevated levels of OTA $(38,41)$. In addition, a multianalyte profiling panel was utilized to measure plasma levels of nine inflammatory markers. Of these, plasma levels of CXCL10/ IP-10 significantly positively correlated with plasma OTA levels $(r=0.58 ; p=0.002$; Figure 4C). GM-CSF, IFN- $\alpha$, IL12p70, and IL-10 were undetectable in most samples (LLD $=7.15,3.2$, 3.2 , and $3.2 \mathrm{pg} / \mathrm{mL}$, respectively). IFN- $\gamma$, IL- 8 , MCP-1, MIP-1 $\beta$, TNF- $\alpha$, and IL-10 levels did not correlate with OTA plasma levels (median $=6.4,57.3,556.4,64.4$, and $39.5 \mathrm{pg} / \mathrm{mL}$, respectively). The relationship between OTA levels and CXCL10 persisted after adjusting for multiple comparisons.

To further evaluate these relationships, we performed a stepwise, multivariate regression, including variables that were selected a priori, based on their potential to influence immune activation; maternal HIV disease stage (measured by maternal CD4 count), infant age at sample collection, gender, and gestational age at birth, as well as OTA plasma levels. In this multivariate assessment, these three inflammatory markers (CCR5 and HLA-DR expression on CD4+ T cells and plasma CXCL10 levels) remained significantly

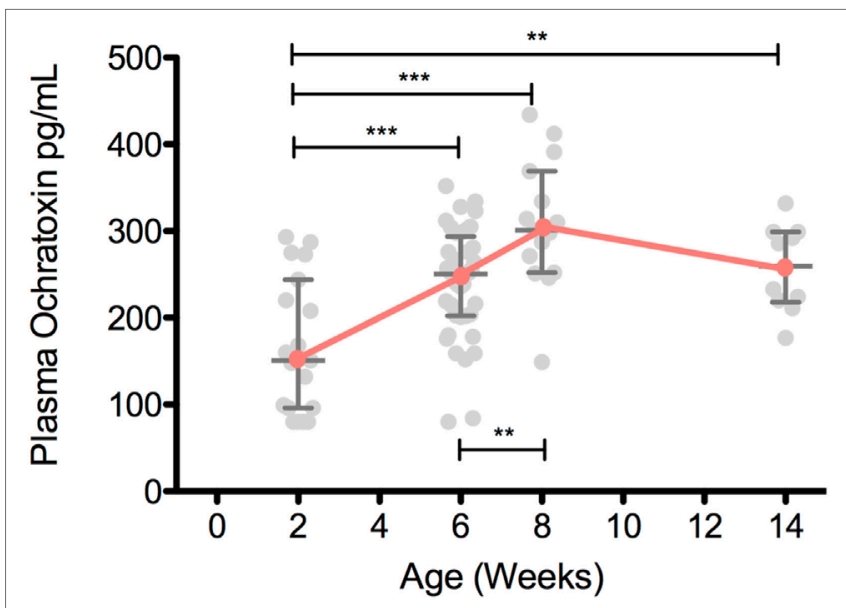

FIGURE 2 | Plasma ochratoxin A (OTA) increases over the first 8 weeks of life in non-breastfed, South African infants. Plasma OTA levels in non-breastfed infants were assessed in 2-week-old ( $n=19)$, 6-week-old $(n=40)$,

8 -week-old $(n=15)$, and 14-week-old $(n=11)$ infants. Pairwise comparisons were tested with a Student's $t$-test. All comparisons with a $p$-value less than 0.05 are shown above. Median and interquartile range are plotted for each time point. ${ }^{\star * *} p<0.001,{ }^{* *} p<0.01,{ }^{*} p<0.05$. All infants were HIV-exposed. 
associated with plasma levels of OTA (Table 2). Specifically, for every $100 \mathrm{pg} / \mathrm{mL}$ increase in plasma OTA levels, the percentage of CD4+ cells expressing CCR5 increased by 1.5 -fold, the percentage

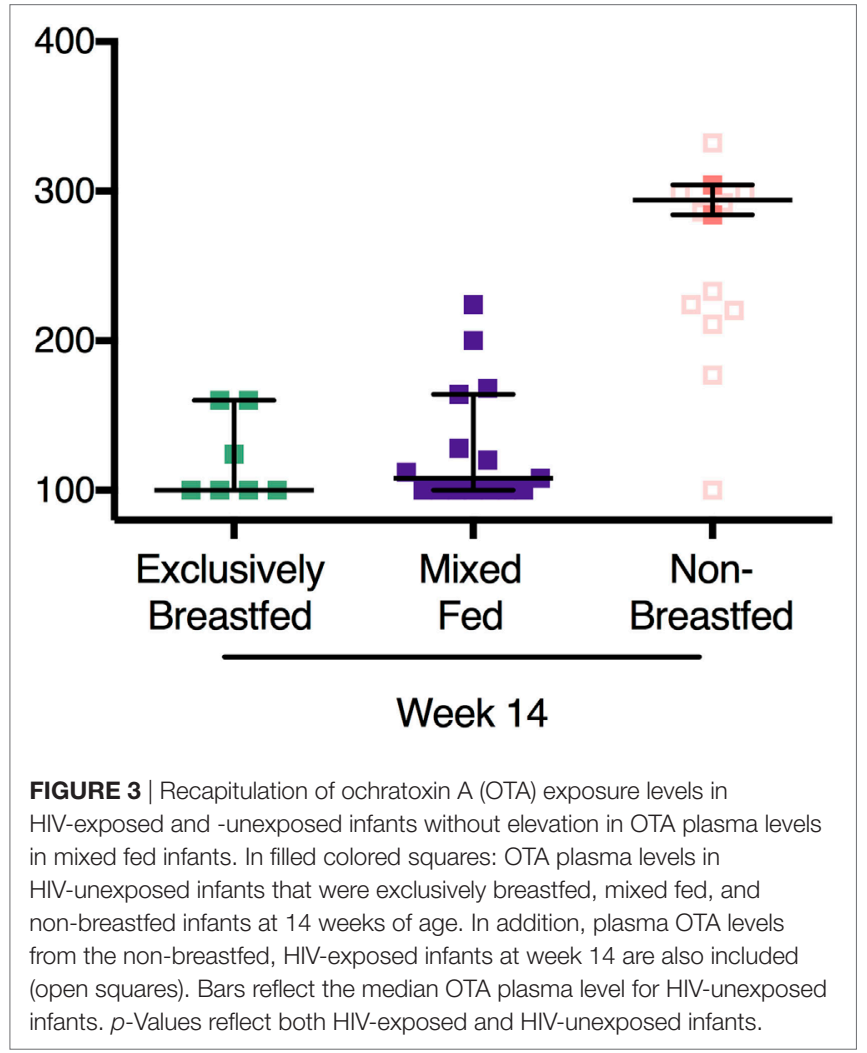

of CD4+ cells expressing HLA-DR increased by 10 -fold, and CXCL10 plasma levels increase by 2.5 -fold. Indeed, in contrast to the other factors evaluated, only OTA plasma levels remained significantly correlated with these inflammatory markers.

\section{Sources of OTA in Exposure for South African Infants}

The findings from this study suggest that South African infants in our study are exposed to OTA via a non-breast milk source. To assess potential sources of OTA in the diet of non-breastfed infants, we measured OTA levels in the four most common, non-breast milk foods given to infants in our study per maternal report. This included the infant formula provided free-of-charge to HIV-infected mothers, and three infant cereals commercially available in Khayelitsha, South Africa. Analysis of OTA levels determined that each of the four infant food samples had less than $0.8 \mu \mathrm{g}$ OTA per $\mathrm{kg}$ of food, the lower limit of detection for the assay. Following this result, we hypothesize that alternative sources of OTA contamination exist.

\section{DISCUSSION}

Here, we evaluated an understudied immune-modulating factor, OTA, for its potential to influence immune activation in infants residing in Khayelitsha, South Africa. HIV is a major issue in this population as $33 \%$ of all pregnant women at this site tested positive for HIV in 2010 (58). The higher rate of disease progression in HIV-infected infants that are replacement fed has, historically, been attributed to poor nutritional intake or exposure to increased levels of pathogens (42-46). Our focus on non-breastfeeding
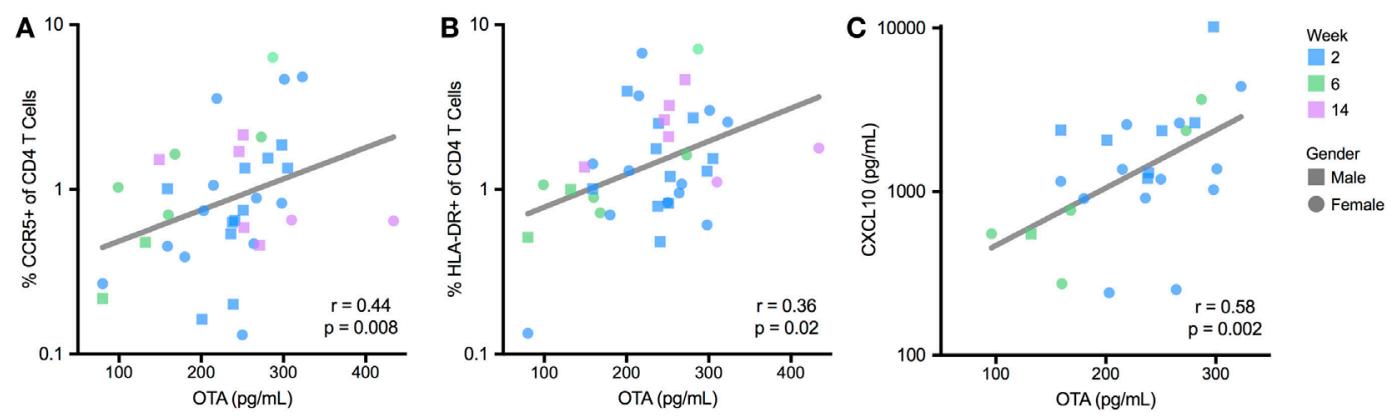

FIGURE 4 | Plasma ochratoxin A (OTA) correlates with markers of immune activation in BCG-unvaccinated, non-breastfed infants. T cell activation, reported as a percentage of CCR5 (A) and HLADR-expressing CD4 T cells (B), was quantified by flow cytometry, and plasma CXCL10 levels (C) were quantified by multiplex immunoassay. $R$ and $p$-value reflect Spearman correlation. For (A-C), lines reflect the best-fit, univariate, linear correlation. CXCL10 levels were not quantified for 8-week-old infants. All infants were HIV-exposed.

TABLE 2 | Ochratoxin A (OTA) is the only immune modulatory factor consistently correlated with immune activation in multivariate analysis.

\begin{tabular}{|c|c|c|c|c|c|c|c|c|c|c|}
\hline & \multicolumn{2}{|c|}{ OTA (pg/mL) } & \multicolumn{2}{|c|}{ Male gender } & \multicolumn{2}{|c|}{ Gestational age } & \multicolumn{2}{|c|}{ Maternal CD4 } & \multicolumn{2}{|c|}{ Visit age } \\
\hline & Coefficient & $p$-Value & Coefficient & $p$-Value & Coefficient & $p$-Value & Coefficient & $p$-Value & Coefficient & $p$-Value \\
\hline $\log _{10}(C D 4 C C R 5)$ & 0.002 & 0.01 & ns & ns & ns & ns & ns & ns & ns & ns \\
\hline $\log _{10}(C D 4 H L A-D R)$ & 0.01 & 0.005 & ns & ns & ns & ns & ns & ns & ns & ns \\
\hline $\log _{10}(C X C L 10 / I P-10)$ & 0.004 & 0.004 & 0.24 & 0.10 & ns & ns & ns & ns & ns & ns \\
\hline
\end{tabular}

Coefficient and $p$-values for variables with $p<0.1$ for the minimum, stepwise multivariate analyses.

NS: $p>0.1$. 
infants at risk for acquiring HIV allows for a direct comparison between a patient population at risk of disease acquisition and an immune-modulating factor (OTA) that can influence target cells for viral infection. However, since we have no clinical outcomes reported in our study, we do not wish to overstate the role of OTA on HIV acquisition/disease progression or all-cause mortality.

Environmental and food contamination of OTA occur worldwide, but exposure levels vary significantly across the globe (47). Here we report, for the first time, that non-breast fed infants, but not exclusively breastfed or mixed fed infants, have elevated levels of OTA within the first weeks of life. In fact, the plasma levels of OTA detected in our study are consistent with the plasma levels observed in communities with sufficiently high levels of exposure that they are described as OTA-endemic (16). In addition, these increased levels of OTA correlated with elevated levels of activated CD4 T cells (CCR5+ and HLA-DR+) and an inflammatory chemokine associated with Th1 T cell mobilization and activation, CXCL10. Increased HLA-DR, CCR5, and CXCL10 expression has been implicated in the pathogenesis of key causes of infant mortality in Africa, including HIV (38, 48-50), lowerrespiratory infections $(51,52)$, sepsis $(53)$, encephalopathy (54), and meningitis (55). While we cannot rule out that plasma OTA levels are merely a biomarker for increased food antigen exposure, our study is the first to identify OTA at high levels in infants consuming non-breast milk foods. Therefore, OTA has the potential to increase morbidity and mortality in HIVuninfected infants, and worsen HIV disease progression in HIV-infected infants.

It is important to consider our findings in the context of the nutritional reality faced by individuals in many low-income communities, including those living in Khayelitsha (56). It is well documented that deficiencies in antioxidants, such as vitamins $\mathrm{C}$, $\mathrm{E}$, and selenium, remain common in many countries, including South Africa (57). OTA impacts the immune system, in part, by inducing production of reactive oxygen species, while inhibiting cellular antioxidant pathways $(30,31)$. Therefore, deficits in exogenous antioxidants could potentiate OTA's immune activation in communities with poor access to quality nutrition. This is particularly important in the context of HIV infection, since oxidative stress increases levels of immune activation and HIV viral replication (32). This mechanism suggests that addition of exogenous antioxidants may be an effective and feasible means of inhibiting OTA-mediated immune activation. This finding provides a potential mechanism for the increased morbidity and mortality of formula-fed infants in sub-Saharan Africa, regardless of HIV status.

Although the source of OTA has not been identified, the increase in OTA only in non-breastfed infants implicates nonbreast milk food contamination, either during manufacturing or during storage or preparation in the home, as the source of this toxin. This source could, therefore, be from soil fungus in the home, or fungal contamination of water due to communal water sources and poor sanitation. We further speculate that since the formula and cereals tested were not determined to have detectable levels of OTA, storage and preparation techniques that minimize soil or water OTA contamination of formula and cereals would have beneficial health outcomes to infants, irrespective of HIV status. However, the greatest benefit will likely be realized in HIVinfected infants for whom elevated levels of oxidative stress and inflammation can exacerbate HIV disease progression.

Infants in South Africa are exposed to the food borne, soilassociated toxin OTA when consuming non-breast milk foods. Increased plasma OTA levels are associated with increased activation of immune cells with multiple functions, including HIV target cells. Identifying sources and reducing levels of OTA in infants from low-income countries would likely result in immune benefits, particularly in HIV-exposed or -infected infants.

\section{ETHICS STATEMENT}

This study was carried out in accordance with the recommendations of University of Cape Town and University of Washington IRB Committees with written informed consent from all subjects. All subjects gave written informed consent in accordance with the Declaration of Helsinki. The protocol was approved by the University of Cape Town and University of Washington IRB Committees.

\section{AUTHOR CONTRIBUTIONS}

LW, DS, and HJ conceptualized this project. HJ oversaw the recruitment of study subjects. LW and $\mathrm{HJ}$ collected and analyzed the data. LW, MW, and BF created the tables and figures. LW, MW, $\mathrm{BF}$, and DS prepared the manuscript. All authors provided leadership and advice on the design, implementation, and completion of the project.

\section{ACKNOWLEDGMENTS}

The authors are grateful to the Western Cape Department of Health for allowing use of their premises and the study staff, Nonkonzo Dziba and Eunice Mhlamba, for assistance with recruitment and follow-up. Some of the data described was included in abstracts presented at the Infectious Disease Society of Obstetrics and Gynecology Conference 2016 and the American Academy of Immunology Conference in 2013.

\section{FUNDING}

This work was supported in part by the following National Institutes of Health awards: NIDCR grant R01-DE023047 to DS, NIEHS grant F30-ES022535 to LW, University of Washington Center For AIDS Research grant P30-AI027757 supported by the following NIH Institutes and Centers (NIAID, NCI, NIMH, NIDA, NICHD, NHLBI, NIA, NIGMS, NIDDK) to LW and K08-HD NICHD K08HD069201 to HJ. This work was also partially funded by an Elizabeth Glaser Pediatric AIDS Foundation Grant MV-00-9-900-01871-0-00 and by a Thrasher Foundation Early Career Award to HJ (Grant number NR-0095). 


\section{REFERENCES}

1. Ip S, Chung M, Raman G, Chew P, Magula N, DeVine D, et al. Breastfeeding and maternal and infant health outcomes in developed countries. Evid Rep Technol Assess (Full Rep) (2007) (153):1-186.

2. Penders J, Stobberingh EE, Thijs C, Adams H, Vink C, van Ree R, et al. Molecular fingerprinting of the intestinal microbiota of infants in whom atopic eczema was or was not developing. Clin Exp Allergy (2006) 36(12): 1602-8. doi:10.1111/j.1365-2222.2006.02599.x

3. Le Huerou-Luron I, Blat S, Boudry G. Breast- v. formula-feeding: impacts on the digestive tract and immediate and long-term health effects. Nutr Res Rev (2010) 23(1):23-36. doi:10.1017/S0954422410000065

4. Dogra S, Sakwinska O, Soh SE, Ngom-Bru C, Bruck WM, Berger B, et al. Rate of establishing the gut microbiota in infancy has consequences for future health. Gut Microbes (2015) 6(5):321-5. doi:10.1080/19490976.2015.1078051

5. WHO. HIV Transmission through Breastfeeding: A Review of the Available Evidence: 2007 Update. Geneva, Switzerland: WHO Press (2008).

6. Goga AE, Doherty T, Jackson DJ, Sanders D, Colvin M, Chopra M, et al. Infant feeding practices at routine PMTCT sites, South Africa: results of a prospective observational study amongst HIV exposed and unexposed infants - birth to 9 months. Int Breastfeed J (2012) 7:4. doi:10.1186/1746-4358-7-4

7. Coutsoudis A, Pillay K, Spooner E, Coovadia HM, Pembrey L, Newell ML. Morbidity in children born to women infected with human immunodeficiency virus in South Africa: does mode of feeding matter? Acta Paediatr (2003) 92(8):890-5. doi:10.1111/j.1651-2227.2003.tb00620.x

8. Taha TE, Kumwenda NI, Hoover DR, Kafulafula G, Fiscus SA, Nkhoma C, et al. The impact of breastfeeding on the health of HIV-positive mothers and their children in sub-Saharan Africa. Bull World Health Organ (2006) 84(7):546-54. doi:10.2471/BLT.05.027664

9. Rossenkhan R, Novitsky V, Sebunya TK, Leidner J, Hagan JE, Moyo S, et al. Infant feeding practices were not associated with breast milk HIV-1 RNA levels in a randomized clinical trial in Botswana. AIDS Behav (2012) 16(5):1260-4. doi:10.1007/s10461-011-0035-7

10. Meehan CL, Roulette JW. Early supplementary feeding among central African foragers and farmers: a biocultural approach. Soc Sci Med (2013) 96:112-20. doi:10.1016/j.socscimed.2013.07.029

11. Liu Z, Hultin LE, Cumberland WG, Hultin P, Schmid I, Matud JL, et al. Elevated relative fluorescence intensity of CD38 antigen expression on CD8+ T cells is a marker of poor prognosis in HIV infection: results of 6 years of follow-up. Cytometry (1996) 26(1):1-7. doi:10.1002/(SICI)1097-0320 (19960315)26:1<1:AID-CYTO1>3.0.CO;2-L

12. Giorgi JV, Lyles RH, Matud JL, Yamashita TE, Mellors JW, Hultin LE, et al. Predictive value of immunologic and virologic markers after long or short duration of HIV-1 infection. J Acquir Immune Defic Syndr (2002) 29(4):346-55. doi:10.1097/00126334-200204010-00004

13. Odhav B, Naicker V. Mycotoxins in South African traditionally brewed beers. Food Addit Contam (2002) 19(1):55-61. doi:10.1080/02652030110053426

14. Shephard GS, Fabiani A, Stockenstrom S, Mshicileli N, Sewram V. Quantitation of ochratoxin A in South African wines. J Agric Food Chem (2003) 51(4):1102-6. doi:10.1021/jf0259866

15. Shephard GS, Burger HM, Gambacorta L, Gong YY, Krska R, Rheeder JP, et al. Multiple mycotoxin exposure determined by urinary biomarkers in rural subsistence farmers in the former Transkei, South Africa. Food Chem Toxicol (2013) 62:217-25. doi:10.1016/j.fct.2013.08.040

16. Koszegi T, Poor M. Ochratoxin A: molecular interactions, mechanisms of toxicity and prevention at the molecular level. Toxins (Basel) (2016) 8(4):111. doi:10.3390/toxins 8040111

17. Elmholt S, Hestbjerg H. Field ecology of the ochratoxin A-producing Penicillium verrucosum: survival and resource colonisation in soil. Mycopathologia (1999) 147(2):67-81. doi:10.1023/A:1007003106343

18. Mortensen GK, Strobel BW, Hansen HC. Determination of zearalenone and ochratoxin A in soil. Anal Bioanal Chem (2003) 376(1):98-101. doi:10.1007/ s00216-003-1863-8

19. Leong SL, Hocking AD, Scott ES. Aspergillus species producing ochratoxin A: isolation from vineyard soils and infection of Semillon bunches in Australia. J Appl Microbiol (2007) 102(1):124-33. doi:10.1111/j.1365-2672.2006.03056.x

20. Qi TF, Renaud JB, McDowell T, Seifert KA, Yeung KK, Sumarah MW. Diversity of mycotoxin-producing black aspergilli in Canadian vineyards. J Agric Food Chem (2016) 64(7):1583-9. doi:10.1021/acs.jafc.5b05584
21. Mata AT, Ferreira JP, Oliveira BR, Batoreu MC, Barreto Crespo MT, Pereira VJ, et al. Bottled water: analysis of mycotoxins by LC-MS/MS. Food Chem (2015) 176:455-64. doi:10.1016/j.foodchem.2014.12.088

22. Varga J, Kevei E, Rinyu E, Teren J, Kozakiewicz Z. Ochratoxin production by Aspergillus species. Appl Environ Microbiol (1996) 62(12):4461-4.

23. Vega FE, Posada F, Peterson SW, Gianfagna TJ, Chaves F. Penicillium species endophytic in coffee plants and ochratoxin A production. Mycologia (2006) 98(1):31-42. doi:10.3852/mycologia.98.1.31

24. Stoev SD. Studies on some feed additives and materials giving partial protection against the suppressive effect of ochratoxin A on egg production of laying hens. Res Vet Sci (2010) 88(3):486-91. doi:10.1016/j.rvsc.2009.12.007

25. Assaf H, Azouri H, Pallardy M. Ochratoxin A induces apoptosis in human lymphocytes through down regulation of Bcl-xL. Toxicol Sci (2004) 79(2):33544. doi:10.1093/toxsci/kfh123

26. Alvarez-Erviti L, Leache C, Gonzalez-Penas E, de Cerain AL. Alterations induced in vitro by ochratoxin A in rat lymphoid cells. Hum Exp Toxicol (2005) 24(9):459-66. doi:10.1191/0960327105ht554oa

27. Al-Anati L, Petzinger E. Immunotoxic activity of ochratoxin A. J Vet Pharmacol Ther (2006) 29(2):79-90. doi:10.1111/j.1365-2885.2006.00718.x

28. Bernardini C, Grilli E, Duvigneau JC, Zannoni A, Tugnoli B, Gentilini F, et al. Cellular stress marker alteration and inflammatory response in pigs fed with an ochratoxin contaminated diet. Res Vet Sci (2014) 97(2):244-50. doi:10.1016/j.rvsc.2014.07.018

29. Periasamy R, Kalal IG, Krishnaswamy R, Viswanadha V. Quercetin protects human peripheral blood mononuclear cells from OTA-induced oxidative stress, genotoxicity, and inflammation. Environ Toxicol (2014) 64(7):1583-9. doi:10.1002/tox.22096

30. Ramyaa P, Krishnaswamy R, Padma VV. Quercetin modulates OTA-induced oxidative stress and redox signalling in HepG2 cells - up regulation of Nrf2 expression and down regulation of NF-kappaB and COX-2. Biochim Biophys Acta (2014) 1840(1):681-92. doi:10.1016/j.bbagen.2013.10.024

31. Gan F, Zhang Z, Hu Z, Hesketh J, Xue H, Chen X, et al. Ochratoxin A promotes porcine circovirus type 2 replication in vitro and in vivo. Free Radic Biol Med (2015) 80:33-47. doi:10.1016/j.freeradbiomed.2014.12.016

32. Malorni W, Rivabene R, Lucia BM, Ferrara R, Mazzone AM, Cauda R, et al. The role of oxidative imbalance in progression to AIDS: effect of the thiol supplier N-acetylcysteine. AIDS Res Hum Retroviruses (1998) 14(17):1589-96. doi:10.1089/aid.1998.14.1589

33. Gasper MA, Hesseling AC, Mohar I, Myer L, Azenkot T, Passmore JS, et al. BCG vaccination induces HIV target cell activation in HIV-exposed infants in a randomized trial. JCI Insight (2017) 2(7):e91963. doi:10.1172/jci. insight.91963

34. Soares AP, Kwong Chung CK, Choice T, Hughes EJ, Jacobs G, van Rensburg EJ, et al. Longitudinal changes in $\mathrm{CD} 4(+) \mathrm{T}$-cell memory responses induced by BCG vaccination of newborns. J Infect Dis (2013) 207(7):1084-94. doi:10.1093/infdis/jis941

35. Team RDC. R: A Language and Environment for Statistical Computing. Vienna, Austria: R Foundation for Statistical Computing (2008).

36. Holm S. A simple sequentially rejective multiple test procedure. Scand J Stat (1979) 6(2):65-70.

37. Tchakoute CT, Hesseling AC, Kidzeru EB, Gamieldien H, Passmore JA, Jones CE, et al. Delaying BCG vaccination until 8 weeks of age results in robust BCG-specific T-cell responses in HIV-exposed infants. J Infect Dis (2015) 211(3):338-46. doi:10.1093/infdis/jiu434

38. Lederman MM, Penn-Nicholson A, Cho M, Mosier D. Biology of CCR5 and its role in HIV infection and treatment. JAMA (2006) 296(7):815-26. doi:10.1001/jama.296.7.815

39. Endl E, Gerdes J. The Ki-67 protein: fascinating forms and an unknown function. Exp Cell Res (2000) 257(2):231-7. doi:10.1006/excr.2000.4888

40. Quarona V, Zaccarello G, Chillemi A, Brunetti E, Singh VK, Ferrero E, et al. CD38 and CD157: a long journey from activation markers to multifunctional molecules. Cytometry B Clin Cytom (2013) 84(4):207-17. doi:10.1002/ cyto.b. 21092

41. Carnathan DG, Wetzel KS, Yu J, Lee ST, Johnson BA, Paiardini M, et al. Activated CD4+CCR5 + T cells in the rectum predict increased SIV acquisition in SIVGag/Tat-vaccinated rhesus macaques. Proc Natl Acad Sci U S A (2015) 112(2):518-23. doi:10.1073/pnas.1407466112

42. Blanche S, Tardieu M, Duliege A, Rouzioux C, Le Deist F, Fukunaga K, et al. Longitudinal study of 94 symptomatic infants with perinatally acquired 
human immunodeficiency virus infection. Evidence for a bimodal expression of clinical and biological symptoms. Am J Dis Child (1990) 144(11):1210-5. doi:10.1001/archpedi.1990.02150350042021

43. Natural history of vertically acquired human immunodeficiency virus-1 infection. The European Collaborative Study. Pediatrics (1994) 94(6 Pt 1): 815-9.

44. Bobat R, Moodley D, Coutsoudis A, Coovadia H. Breastfeeding by HIV-1infected women and outcome in their infants: a cohort study from Durban, South Africa. AIDS (1997) 11(13):1627-33. doi:10.1097/00002030-19971300000012

45. Spira R, Lepage P, Msellati P, Van De Perre P, Leroy V, Simonon A, et al. Natural history of human immunodeficiency virus type 1 infection in children: a five-year prospective study in Rwanda. Mother-to-Child HIV-1 Transmission Study Group. Pediatrics (1999) 104(5):e56. doi:10.1542/peds.104.5.e56

46. Mbori-Ngacha D, Nduati R, John G, Reilly M, Richardson B, Mwatha A, et al. Morbidity and mortality in breastfed and formula-fed infants of HIV-1infected women: a randomized clinical trial. JAMA (2001) 286(19):2413-20. doi:10.1001/jama.286.19.2413

47. Duarte SC, Pena A, Lino CM. A review on ochratoxin A occurrence and effects of processing of cereal and cereal derived food products. Food Microbiol (2010) 27(2):187-98. doi:10.1016/j.fm.2009.11.016

48. Meditz AL, Haas MK, Folkvord JM, Melander K, Young R, McCarter M, et al. HLA-DR+ CD38+ CD4+ T lymphocytes have elevated CCR5 expression and produce the majority of R5-tropic HIV-1 RNA in vivo. J Virol (2011) 85(19):10189-200. doi:10.1128/JVI.02529-10

49. Durudas A, Milush JM, Chen HL, Engram JC, Silvestri G, Sodora DL. Elevated levels of innate immune modulators in lymph nodes and blood are associated with more-rapid disease progression in simian immunodeficiency virus-infected monkeys. J Virol (2009) 83(23):12229-40. doi:10.1128/JVI. 01311-09

50. Liovat AS, Rey-Cuille MA, Lecuroux C, Jacquelin B, Girault I, Petitjean G, et al. Acute plasma biomarkers of $\mathrm{T}$ cell activation set-point levels and of disease progression in HIV-1 infection. PLoS One (2012) 7(10):e46143. doi:10.1371/journal.pone.0046143

51. Hull J, Rowlands K, Lockhart E, Moore C, Sharland M, Kwiatkowski D. Variants of the chemokine receptor CCR5 are associated with severe bronchiolitis caused by respiratory syncytial virus. J Infect Dis (2003) 188(6):904-7. doi:10.1086/377587
52. McNamara PS, Flanagan BF, Hart CA, Smyth RL. Production of chemokines in the lungs of infants with severe respiratory syncytial virus bronchiolitis. J Infect Dis (2005) 191(8):1225-32. doi:10.1086/428855

53. Cuenca AG, Wynn JL, Kelly-Scumpia KM, Scumpia PO, Vila L, Delano MJ, et al. Critical role for CXC ligand 10/CXC receptor 3 signaling in the murine neonatal response to sepsis. Infect Immun (2011) 79(7):2746-54. doi:10.1128/ IAI.01291-10

54. Armah HB, Wilson NO, Sarfo BY, Powell MD, Bond VC, Anderson W, et al. Cerebrospinal fluid and serum biomarkers of cerebral malaria mortality in Ghanaian children. Malar J (2007) 6:147. doi:10.1186/1475-2875-6-147

55. Cavcic A, Tesovic G, Gorenec L, Grgic I, Benic B, Lepej SZ. Concentration gradient of CXCL10 and CXCL11 between the cerebrospinal fluid and plasma in children with enteroviral aseptic meningitis. Eur J Paediatr Neurol (2011) 15(6):502-7. doi:10.1016/j.ejpn.2011.05.008

56. Drimie S, Faber M, Vearey J, Nunez L. Dietary diversity of formal and informal residents in Johannesburg, South Africa. BMC Public Health (2013) 13:911. doi:10.1186/1471-2458-13-911

57. Labadarios D, Steyn NP, Maunder E, MacIntryre U, Gericke G, Swart R, et al. The National Food Consumption Survey (NFCS): South Africa, 1999. Public Health Nutr (2005) 8(5):533-43. doi:10.1079/PHN2005816

58. Khayelitsha Annual Activity Report, 2008-2009. In: Western Cape Province Department of Health, editor. Médecins Sans Frontières, City of Cape Town Department of Health, University of Cape Town Centre for Infectious Disease Epidemiology and Research. Cape Town, South Africa: Médecins Sans Frontières (2010).

Conflict of Interest Statement: The authors declare that the research was conducted in the absence of any commercial or financial relationships that could be construed as a potential conflict of interest.

The reviewer YZ and handling editor declared their shared affiliation.

Copyright (๑) 2017 Wood, Wood, Fisher, Jaspan and Sodora. This is an open-access article distributed under the terms of the Creative Commons Attribution License (CC BY). The use, distribution or reproduction in other forums is permitted, provided the original author(s) or licensor are credited and that the original publication in this journal is cited, in accordance with accepted academic practice. No use, distribution or reproduction is permitted which does not comply with these terms. 